\title{
Passively $Q$-switched diode-pumped Er:YAG solid-state laser
}

\author{
Adrien Aubourg, ${ }^{1,2, *}$ Julien Didierjean, ${ }^{2}$ Nicolas Aubry, ${ }^{2}$ François Balembois, ${ }^{1}$ and Patrick Georges ${ }^{1}$ \\ ${ }^{1}$ Laboratoire Charles Fabry, Institut d'Optique, CNRS, Univ Paris-Sud-2 Av A. Fresnel, 91127 Palaiseau Cedex, France \\ ${ }^{2}$ Fibercryst_La Doua, Bat. l'Atrium, Bd Latarjet, F-69616 Villeurbanne, France \\ *Corresponding author: adrien.aubourg@institutoptique.fr
}

Received January 10, 2013; revised February 4, 2013; accepted February 4, 2013;

posted February 5, 2013 (Doc. ID 183285); published March 13, 2013

\begin{abstract}
We demonstrated laser operation of a passively $Q$-switched diode-pumped Er:YAG solid-state laser emitting at 1645 or $1617 \mathrm{~nm}$ depending on the initial transmission of the Cr:ZnSe saturable absorber. The crystal emitted up to $10 \mathrm{~W}$ at $1645 \mathrm{~nm}$ and up to $8 \mathrm{~W}$ at $1617 \mathrm{~nm}$ in CW mode while pumped with $65 \mathrm{~W}$ of incident pump power at $1533 \mathrm{~nm}$. In passive $Q$-switched mode with $40 \mathrm{~W}$ of incident power, a Cr:ZnSe saturable absorber with initial transmission of $85 \%$ led to $330 \mu \mathrm{J}$ pulse energy, $61 \mathrm{~ns}$ pulse duration at a repetition rate of $1460 \mathrm{~Hz}$ at $1645 \mathrm{~nm}$. An $80 \%$ initial transmission Cr:ZnSe sample led to $510 \mu \mathrm{J}$ energy pulses, $41 \mathrm{~ns}$ pulse duration at a repetition rate of $820 \mathrm{~Hz}$ with a central wavelength change from 1645 to $1617 \mathrm{~nm}$. This is the first reported passively $Q$-switched diode-pumped Er:YAG laser operating on the ${ }^{4} \mathrm{I}_{13 / 2} \rightarrow{ }^{4} \mathrm{I}_{15 / 2}$ transition. (c) 2013 Optical Society of America

OCIS codes: $140.3580,140.3540,140.3500,140.3070$.
\end{abstract}

Direct resonant pumping of Er:YAG is a laser configuration studied for compact eye-safe emitters which applications require kilometer range propagation in the atmosphere, like active imaging or Lidar. The pump sources are either Er:Yb fiber lasers operating at $1532 \mathrm{~nm}$ [1] or laser diodes emitting at $1470 \mathrm{~nm}$ [2] and $1532 \mathrm{~nm}[\underline{3}, \underline{4}]$. For several configurations, the laser emission naturally occurred at $1645 \mathrm{~nm}$. Indeed, although the emission cross section is higher at $1617 \mathrm{~nm}$, the needed population inversion for transparency at $1617 \mathrm{~nm}$ is $14 \%$ of the total population (at $300 \mathrm{~K}$ ) whereas it is only $9 \%$ at $1645 \mathrm{~nm}$ [5]. Unfortunately, a methane absorption line exists at this wavelength in the atmosphere with a typical value of $0.1 \mathrm{~km}^{-1}[\underline{6}$. One way to increase the range of the emitter is to use the $1617 \mathrm{~nm}$ emission line, which is free of absorption. The $1617 \mathrm{~nm}$ wavelength was observed in free running at temperature below $90 \mathrm{~K}$ [7]], in high loss cavities [5] or with injection seeding [8] with a diffraction limited $\mathrm{Er}: \mathrm{Yb}$ fiber laser as pump source. Recently, directly diode-pumped emitters achieved $8 \mathrm{~W}$ in $\mathrm{CW}$ mode with $100 \mathrm{~W}$ of incident pump power in a waveguided configuration [9] , and $11.8 \mathrm{~mJ}$ pulses in actively $Q$-switched regime [10].

Successfull attempts of passive $Q$-switch (QS) has been recorded for the ${ }^{4} \mathrm{I}_{13 / 2} \rightarrow{ }^{4} \mathrm{I}_{15 / 2}$ transition at $1.6 \mu \mathrm{m}$ with erbium fiber laser as pump source $[11,12]$ or Er:glass flashed pump systems with low repetition rate [13]. The fairly complexity of the pump setup used in these experiments reduces the benefit of the use of a saturable absorber as QS system. On our way to develop compact and simple sources for eye-safe applications [14], we investigated passively $Q$-switched diode-pumped Er:YAG cavities for laser operation at $1617 \mathrm{~nm}$. For Er:YAG, such configuration has been demonstrated at $2.9 \mu \mathrm{m}$ [15] with $3 \mu \mathrm{J}$ of pulse energy.

In this Letter, we demonstrate for the first time a direct diode-pumped Er:YAG solid-state laser passively $Q$-switched operating at 1645 or $1617 \mathrm{~nm}$ depending on the initial transmission of the Cr:ZnSe saturable absorber. For that, we used the potential of single crystal fibers (SCFs) for pump confinement and consequently for high inversion population ratio to favor the $1617 \mathrm{~nm}$ laser emission.

An Er:YAG Taranis module produced by Fibercryst, integrating a $750 \mu \mathrm{m}$ diameter, $30 \mathrm{~mm}$ long Er:YAG crystal with a doping concentration of $0.5 \%$ is used as gain medium. The pump light is provided by a fiber-coupled laser diode from QPC with a $400 \mu \mathrm{m}$ core diameter and an NA of 0.22 , delivering up to $60 \mathrm{~W}$ at $1532 \mathrm{~nm}$. Its spectrum is narrowed by an internal grating, down to $1 \mathrm{~nm}$ approximately. The beam is collimated by a $40 \mathrm{~mm}$ focal length doublet and then focused a few millimeters inside the Er:YAG crystal thanks to another $40 \mathrm{~mm}$ focal length doublet. With this setup, we estimate that the pump beam undergoes between two and three reflections in the SCF (Fig. 1), allowing a higher population inversion and a better spatial overlap between the pump and the laser signal than in standard rods. The Er:YAG was antireflection coated on both ends and actively cooled at $12^{\circ} \mathrm{C}$.

A first cavity has been designed for $\mathrm{CW}$ operation (Fig. 2). It consists in one meniscus with a radius of curvature of $100 \mathrm{~mm}$ and dichroic coatings (high transmission at $1532 \mathrm{~nm}$ and high reflectivity at $1617-1645 \mathrm{~nm}$ ), a highly reflective mirror with a radius of curvature of $400 \mathrm{~mm}$, which collimates the laser beam, and a plano output coupler with a transmission of $20 \%$ at $1.6 \mu \mathrm{m}$. The $100 \mu \mathrm{m}$ thick etalon, inserted inside the cavity on the collimated arm, acts as a wavelength selector between 1645 and $1617 \mathrm{~nm}$. The optical length of the cavity is $350 \mathrm{~mm}$.

This setup led to CW output powers up to $10 \mathrm{~W}$ at $1645 \mathrm{~nm}$ (Fig. 3). At $1617 \mathrm{~nm}$, the cavity yielded $8 \mathrm{~W}$ of $\mathrm{CW}$ output power, reaching the state-of-the-art $\mathrm{CW}$

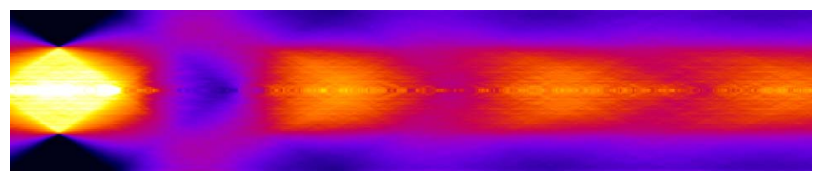

Fig. 1. (Color online) Pump profile inside a $30 \times 0.75 \mathrm{~mm}$ undoped YAG SCF obtained by raytracing simulation (diameter slice along the crystal axis). 


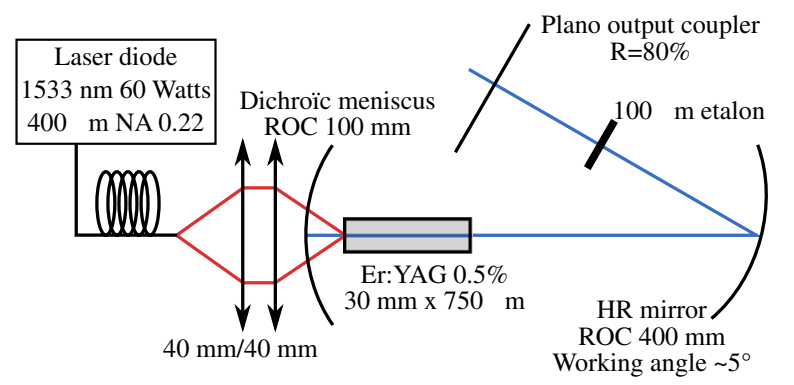

Fig. 2. (Color online) Experimental setup of the directly diode-pumped Er:YAG laser in $\mathrm{CW}$ regime.

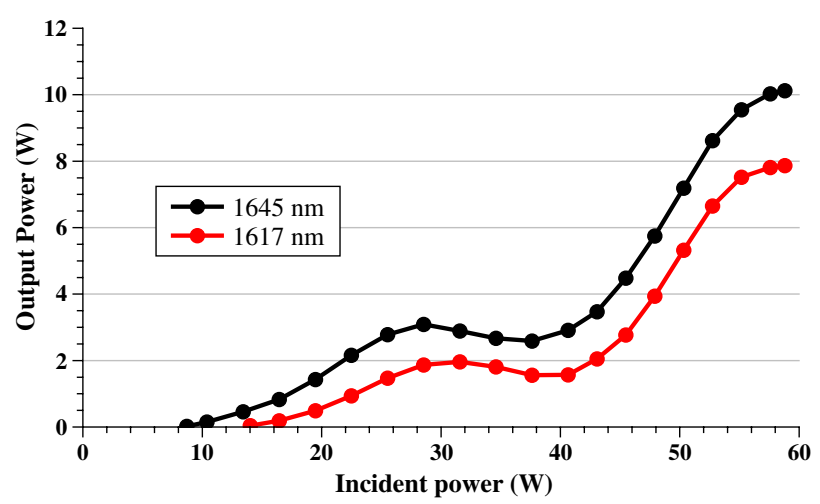

Fig. 3. (Color online) CW output power at 1617 and $1645 \mathrm{~nm}$ versus the incident pump power.

performance of [9] with a better efficiency (pump power reduced by $40 \%)$. The particular shape of the efficiency curve comes from the spectral shift of the laser diode despite the internal grating (same effect with lower wavelength shift already observed in [10]).

For compactness matters, a second cavity has been designed (Fig. 4) and only consists in two concave mirrors with a radius of curvature of $100 \mathrm{~mm}$. Moreover, in view of a low consumption system, the maximum pump power was reduced to $40 \mathrm{~W}$. The first one was highly reflective for 1617 and $1645 \mathrm{~nm}$ and transparent for $1532 \mathrm{~nm}$. The second one was an output coupler with a transmission of $20 \%$ around $1.6 \mu \mathrm{m}$. The optical cavity length is $120 \mathrm{~mm}$. The Cr:ZnSe saturable absorber is inserted just next to the output coupler to decrease the energy density as its damage threshold is lower $\left(\sim 2 \mathrm{~J} / \mathrm{cm}^{2}\right)$ than the damage threshold of the Er:YAG coatings $\left(\sim 6 \mathrm{~J} / \mathrm{cm}^{2}\right)$. No etalon has been inserted inside this cavity.

In CW regime, this laser cavity emits a power of $3.3 \mathrm{~W}$ at $1645 \mathrm{~nm}$ with a threshold pump power of $19 \mathrm{~W}(16 \%$ of

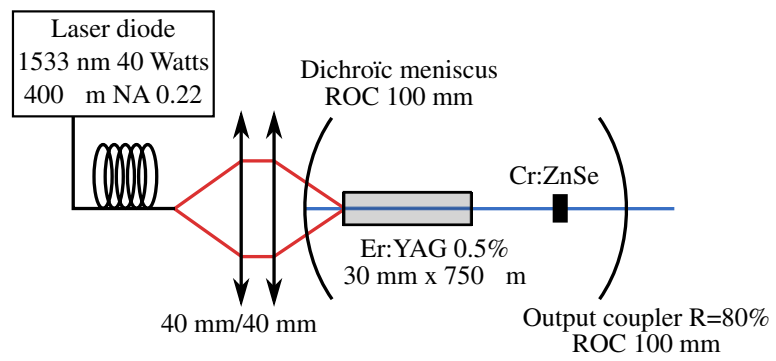

Fig. 4. (Color online) Experimental setup of the passively $Q$-switched directly diode-pumped Er:YAG laser.

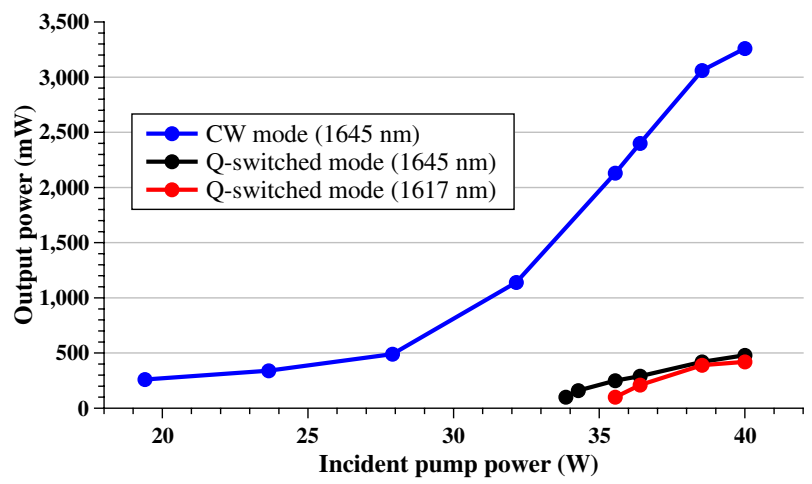

Fig. 5. (Color online) Output power of the laser cavity described in Fig. 4 in CW mode at $1645 \mathrm{~nm}$ and in passive $Q$-switched mode at 1645 and $1617 \mathrm{~nm}$ versus the incident pump power.

slope efficiency) (Fig. 5). The nonresonant pumping at low incident power caused by the pump spectral shift induces the particular shape of the efficiency curve.

Table 1 is an outlook of $Q$-switched regime performance at $40 \mathrm{~W}$ of pump power. Two Cr:ZnSe saturable absorbers from Altechna with different initial transmissions are inserted inside the laser cavity. The average power drops down from $3200 \mathrm{~mW}$ to around $450 \mathrm{~mW}$ (Fig. 5). A saturable absorber with $85 \%$ of initial transmission leads to an emitted wavelength of $1645 \mathrm{~nm}$. But a darker sample (80\% of initial transmission) leads to a wavelength change from 1645 to $1617 \mathrm{~nm}$. This sudden shift has already been observed in [11], and comes from the high losses introduced inside the cavity. In addition, the slightly higher Cr:ZnSe absorption at $1645 \mathrm{~nm}$ compared to $1617 \mathrm{~nm}$ contributes to the wavelength selection. This wavelength shift happens whatever the incident pump power.

Pulse duration has been recorded at $61 \mathrm{~ns}$ at $1645 \mathrm{~nm}$ and $41 \mathrm{~ns}$ at $1617 \mathrm{~nm}$ (Fig. 6) and is insensitive to the

Table 1. Output Performance in $Q$-Switched Regime for Two Different Initial Transmissions $\left(T_{\text {init }}\right)$ of Saturable Absorber at $40 \mathrm{~W}$ of Pump Power

\begin{tabular}{lcccc}
\hline $\begin{array}{l}T_{\text {init }} \\
(\%)\end{array}$ & $\begin{array}{c}\text { Rep. Rate } \\
(\mathrm{Hz})\end{array}$ & $\begin{array}{c}\text { Duration } \\
(\mathrm{ns})\end{array}$ & $\begin{array}{c}\text { Wavelength } \\
(\mathrm{nm})\end{array}$ & $\begin{array}{c}\text { Energy } \\
(\mu \mathrm{J})\end{array}$ \\
\hline 85 & 1460 & 61 & 1645 & 329 \\
80 & 820 & 41 & 1617 & 512 \\
\hline
\end{tabular}

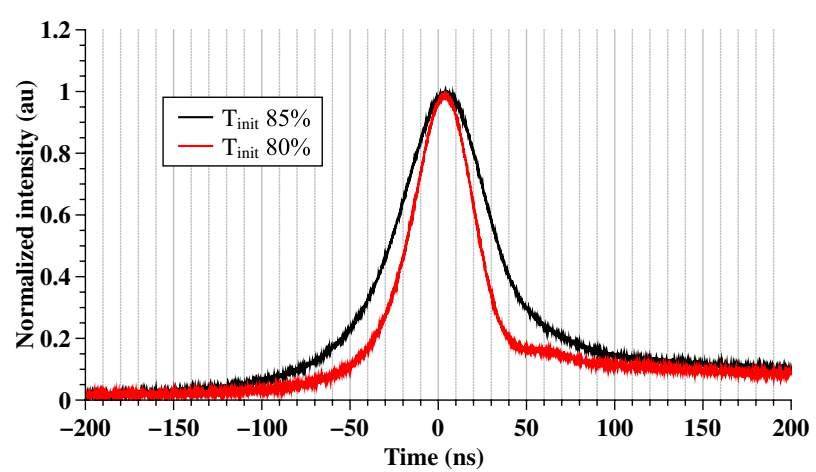

Fig. 6. (Color online) Normalized pulse shapes at full pump power $(40 \mathrm{~W})$. 


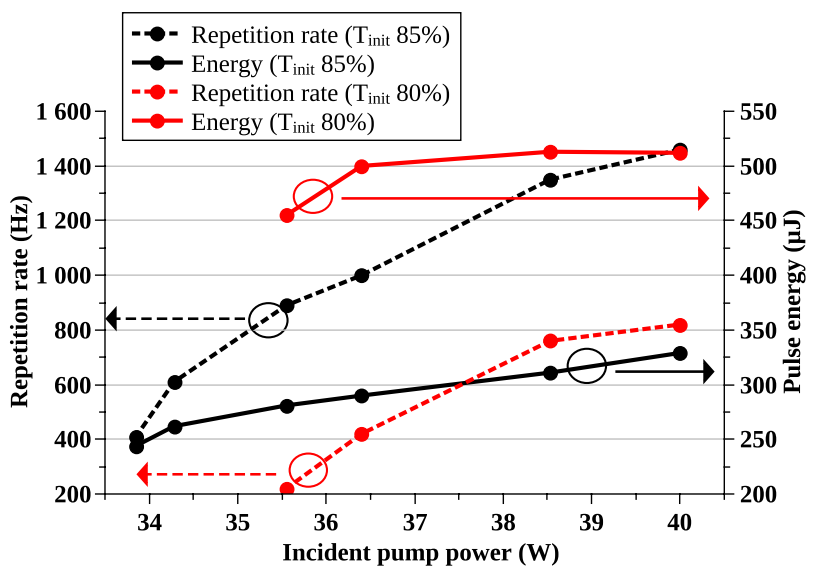

Fig. 7. (Color online) Pulse energy (plain) and repetition rate (dashed) versus the incident pump power for 85\% (black) and $80 \%$ (red) of Cr:ZnSe initial transmission.

pump power, as the cavity losses and the gain before pulses are independent from the pump power in passive $Q$-switched lasers. These pulse durations are not the lowest recorded for $Q$-switched Er:YAG but still belong to low range pulse durations for this type of experiment.

The output $M^{2}$ is equal to 1.6 in CW or $Q$-switched regime at $40 \mathrm{~W}$ of pump power. We did not observed spatial beam filtering from $\mathrm{CW}$ to $\mathrm{QS}$, mainly because of the very low Cr:ZnSe saturation intensity value of $14 \mathrm{~kW} / \mathrm{cm}^{2}$ [16]

In our experiments, repetition rates go from 400 to $1460 \mathrm{~Hz}$ and from 220 to $820 \mathrm{~Hz}$ depending on the saturable absorber's transmission, while pulse energies go from 240 to $330 \mu \mathrm{J}$ and from 455 to $510 \mu \mathrm{J}$ (Fig. 7).

In conclusion, we reported the first results in $Q$-switched operation at 1617 and $1645 \mathrm{~nm}$ of a directly diode-pumped Er:YAG cavity yielding $329 \mu \mathrm{J}$ at $1645 \mathrm{~nm}$ and more than $500 \mu \mathrm{J}$ at $1617 \mathrm{~nm}$. The SCF geometry allowed a pump confinement to raise the population inversion to favor the emission of the $1617 \mathrm{~nm}$ line from the cavity. This work is a first step to add mobility and compactness to laser sources for range detection and Lidar, avoiding the use of water-cooled acousto-optic modulator for active QS operation and fiber laser as a pump source.

This work has been funded by the Direction Générale de l'Armement (112906173).

\section{References}

1. D. Y. Shen, J. K. Sahu, and W. A. Clarkson, Opt. Lett. 31, 754 (2006).

2. N. Chang, N. Simakov, D. Hosken, J. Munch, D. Ottaway, and P. Veitch, Opt. Express 18, 13673 (2010).

3. L. Zhu, M. Wang, J. Zhou, and W. Chen, Opt. Express 19, 26810 (2011).

4. S. Bigotta and M. Eichhorn, Opt. Lett. 35, 2970 (2010).

5. J. W. Kim, D. Y. Shen, J. K. Sahu, and W. A. Clarkson, Opt. Express 16, 5807 (2008).

6. K. Fox, Appl. Opt. 23, 3040 (1984).

7. N. Ter-Gabrielyan, M. Dubinskii, G. A. Newburgh, A. Michael, and L. D. Merkle, Opt. Express 17, 7159 (2009).

8. J. Kim, D. Shen, J. Sahu, and W. Clarkson, IEEE J. Sel. Top. Quantum Electron. 15, 361 (2009).

9. N. Ter-Gabrielyan, V. Fromzel, X. Mu, H. Meissner, and M. Dubinskii, Opt. Express 20, 25554 (2012).

10. M. Wang, L. Zhu, W. Chen, and D. Fan, Opt. Lett. 37, 3732 (2012).

11. R. D. Stultz, V. Leyva, and K. Spariosu, Appl. Phys. Lett. 87, 241118 (2005).

12. Y. Terekhov, D. V. Martyshkin, V. V. Fedorov, I. Moskalev, and S. B. Mirov, in Proceedings of the Conference on Lasers and Electro-Optics (CLEO): Science and Innovations (Optical Society of America, 2012), p. CTu2D.6.

13. M. Němec, H. Jelínková, J. Šulc Karel Nejezchleb, and V. Škoda, in Proceedings of the International Quantum Electronics Conference and Conference on Lasers and Electro-Optics Pacific Rim 2011 (Optical Society of America, 2011), p. C552.

14. A. Aubourg, I. Martial, J. Didierjean, F. Balembois, and P. Georges, Proc. SPIE 8235, 823516 (2012).

15. A. Voronov, V. Kozlovskii, Y. Korostelin, A. Landman, Y. Podmarkov, V. Polushkin, T.-O. Ragimov, Y. Skasyrskii, M. Filipchuk, and M. Frolov, Bull. Lebedev. Phys. Inst. 37, 169 (2010).

16. R. Page, K. Schaffers, L. DeLoach, G. Wilke, F. Patel, J. Tassano, Jr., S. Payne, W. Krupke, K.-T. Chen, and A. Burger, IEEE J. Quantum Electron. 33, 609 (1997). 